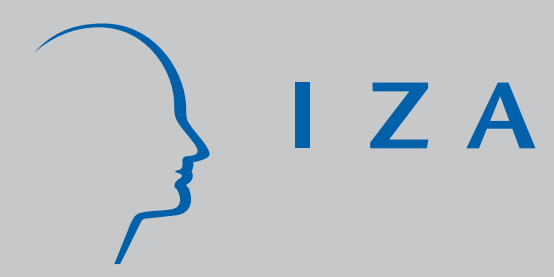

IZA DP No. 4099

Obesity and Labor Market Outcomes: Evidence from the British NCDS

Maarten Lindeboom

Petter Lundborg

Bas van der Klaauw

March 2009 


\title{
Obesity and Labor Market Outcomes: Evidence from the British NCDS
}

\author{
Maarten Lindeboom \\ VU University Amsterdam, Tinbergen Institute, \\ HEB, Netspar and IZA \\ Petter Lundborg \\ VU University Amsterdam, Tinbergen Institute, \\ Netspar, HEP and IZA \\ Bas van der Klaauw \\ VU University Amsterdam, Tinbergen Institute \\ and IZA
}

Discussion Paper No. 4099

March 2009

IZA

P.O. Box 7240

53072 Bonn

Germany

Phone: +49-228-3894-0

Fax: +49-228-3894-180

E-mail: iza@iza.org

Any opinions expressed here are those of the author(s) and not those of IZA. Research published in this series may include views on policy, but the institute itself takes no institutional policy positions.

The Institute for the Study of Labor (IZA) in Bonn is a local and virtual international research center and a place of communication between science, politics and business. IZA is an independent nonprofit organization supported by Deutsche Post Foundation. The center is associated with the University of Bonn and offers a stimulating research environment through its international network, workshops and conferences, data service, project support, research visits and doctoral program. IZA engages in (i) original and internationally competitive research in all fields of labor economics, (ii) development of policy concepts, and (iii) dissemination of research results and concepts to the interested public.

IZA Discussion Papers often represent preliminary work and are circulated to encourage discussion. Citation of such a paper should account for its provisional character. A revised version may be available directly from the author. 


\section{ABSTRACT \\ Obesity and Labor Market Outcomes: Evidence from the British NCDS*}

We study the effect of obesity on wages and employment, using data from the British NCDS. The results show a significant negative association between obesity and labor market outcomes even after controlling for a rich set of demographic, socioeconomic, environmental and behavioral variables. After instrumenting with parental obesity the associations are no longer significant. We show that the intergenerational correlation in obesity is mainly due to genetic variation. However, the instruments do not always pass the overidentification tests and are sometimes weak. We are therefore somewhat sceptical about using parental obesity as an instrument.

JEL Classification: $\quad 110, \mathrm{~J} 10$

Keywords: obesity, wages, employment, labor, endogeneity

Corresponding author:

Petter Lundborg

Department of Economics

Free University Amsterdam

De Boelelaan 1105

1081 HV Amsterdam

The Netherlands

E-mail: plundborg@feweb.vu.nl

\footnotetext{
* We are grateful for the comments made by Stephanie von Hinke-Kessler-Scholder, Owen O'Donnell, and participants at the $17^{\text {th }}$ European Workshop on Econometrics and Health Economics in Coimbra and participants at the 6th IHEA Congress in Copenhagen.
} 


\section{Introduction}

A growing literature focuses on the importance of non-traditional traits such as physical appearance, personality and birth order on labor market success (Hamermesh and Biddle 1994; Mueller and Plug 2006; Kantarevic and Mechoulan 2006). The literature on physical appearance mainly considers three attributes, attractiveness, body mass and height. To date, the effect of body mass has received most attention, reflecting concerns about the sharply increasing obesity rates found in most Western countries (OECD, 2005, p.87). Naturally, this raises the question about any adverse labor market consequences.

Obesity increases the risk of various health problems such as cancer, stroke, diabetes, asthma, hypertension, depression, and arthritis (Abbott et al. 1994; Pi-Sunyer 2002), which may affect the individual's capacity to work. There are however alternative explanations for the effect of obesity on labor market outcomes. Employers may discriminate against obese workers (e.g. Hamermesh and Biddle 1994; Baum and Ford 2004; Rooth 2009). Discrimination is not always clear as in some jobs, such as sales, physical appearance may be directly related to productivity. Furthermore, obesity may be related to non-desirable personality traits potentially affecting productivity. For instance, Puhl and Brownell (2001) and Sobal (2004) revealed public beliefs about obese people, they are thought to be lazier and less socially and intellectually skilled than their non-obese counterparts.

Here we look at the effect of obesity on wages and employment. The previous literature has primarily looked at the effect of obesity on wages, but it may be clear from the above that obesity may also have a direct effect on employment status. This holds in particular for groups that have traditionally lower participation rates like females. Focusing on wages alone may therefore leave out an important aspect of the effect of obesity on labor market outcomes.

Investigating the effect of obesity of labor market outcomes is complicated by potential reversed causality and endogeneity problems. Reversed causality may arise, for instance, because energy dense fattening food is relatively cheap and lower wages increase the demand for such food. Furthermore, there may be unobserved characteristics that vary systematically between obese and nonobese people and these factors may also affect employment and wages. For

instance, people with high discount rates may be more prone to weight-gaining consumption. At the same time, high discount rates make investments in human capital (and thus future labor market outcomes) less attractive (Cawley 2000 and 2004; Baum and Ford 2004).

In this paper we contribute to the literature on the effect of obesity of labor market outcomes. We use data from the British National Child Development Study (NCDS), which is a longitudinal study on around 17,000 individuals born in Great Britain in the week of March 3-9, 1958, who are followed up to 2004, when they were 46 years old. The NCDS has a number of advantages. Since NCDS follows people from birth, it contains extensive information on 
early life conditions that could potentially affect both obesity and labor market outcomes. Even more importantly, it records the height and weight of both the respondent and the respondent's mother and father. Since there is a strong association in body size between a parent and a child, we use parental obesity as instruments. This is an improvement compared to Cawley (2004), who used the Body Mass Index of a sibling as an instrument, for two reasons. First, since parental obesity is available for all respondents, we do not have to rely on the obesity of a sibling, which would restrict the sample to only those where information on a sibling is present. Second, since we have two instruments we are able to perform overidentification tests on our instruments.

Our identification strategy depends on the assumption that there are no other pathways than via the respondent's obesity status in which parental obesity affects the respondent's labor market outcomes. Alternative pathways may be present if genetic or non-genetic factors which affect obesity also have a direct impact on labor market outcomes. There is some evidence, based on twin and adoption studies, suggesting that the association in body weight between biological relatives is due to genetics and that shared environmental factors play no role. However, this finding is not uncontroversial. We exploit the richness of our data and provide some checks for the presence of alternative pathways.

First, our data contain many socioeconomic and demographic characteristics. We show that the strong association between the respondent's obesity status and parental obesity is virtually unaffected when we condition on environmental factors during childhood and adolescence. Conditioning on these factors at the same time makes the association between the respondent's obesity status and labor market outcomes weaker. This might be taken as evidence that it is mainly genetic factors which affect the intergenerational association in obesity. We further test this by exploiting information on adopted children in our data. If the association is only due to genetics, then one would expect no association between the obesity status of adopted children and their adoptee parents. Indeed, we find that the coefficient for adopted children is close to zero, again suggesting that environmental factors play a small role. These results, in sum, provide at least suggestive evidence that parental obesity mainly predicts genetic variation in the respondent's obesity status, making it potentially useful as an instrument.

Our instruments would still be invalid, however, if the same genes that predict obesity also predict labor market outcomes. We therefore generalize the analytical framework of Cawley (2004) by exploiting the panel feature of the NCDS and conduct regressions in first differences. This removes all unobserved, time-invariant, heterogeneity, such as genetic factors correlated with both obesity and labor market success. These estimates may still reflect reverse causality, if shocks in labor market outcomes affect obesity or if the impact of genetic factors differs with the age of the respondent. Finally, we therefore combine the panel feature with our instrumental variable strategy and instrument the change in obesity with parental obesity. 
In our data there is a negative correlation between obesity and the employment probability among women and men and between obesity and wages for women. Although the sizes of these associations become smaller after controlling for a extensive list of controls for cognitive ability and parental inputs they remain negative and significant. Using our instrumental variables strategy, no significant effects of obesity on labor market outcomes remain. We are cautious in interpreting our instrumental variable results, however, since in several specification the instruments do not pass the overidentification tests and in the first-difference specifications the instruments are rather weak. Although the instruments do not perform poorly in all specifications the results raise some sceptism about the use of the body mass of a biological relative as instrument, as first proposed by Cawley (2004).

The structure of the paper is as follows. Section 2 provides a general analytical framework. Section 3 introduces the National Child Development Study data and reports on the variables used in the empirical part. Section 4 discusses the empirical results. Section 5 concludes.

\section{Analytical framework}

In this section we present a general analytical framework that includes the larger part of the frameworks used in the literature, such as for example Cawley (2004).

In the literature on obesity and labor market outcomes, the typical wage $\left(W_{i t}\right)$ equation is:

$$
\ln W_{i t}=O B E S I T Y_{i t} \beta_{t}+X_{i t} \gamma+\mu_{i t}+\epsilon_{i t},
$$

where $O B E S I T Y_{i t}$ is the obesity status of individual $i$ at age $t$ and $X_{i t}$ is a vector of other variables affecting wages. The term $\mu_{i t}$ captures genetic and non-genetic factors which may be time-varying and $\epsilon_{i t}$ is the residual. This equation strongly relates to Cawley (2004), with the exception that we allow the effect of obesity to vary with age $t$. Other labor market outcomes, such as employment, have been analyzed using similar models (see e.g. Lundborg et al. 2007). OLS estimation produces consistent estimates of $\beta_{t}$ only in case the vector $X_{i t}$ contains all variables that both are correlated with obesity and affect wages. However, for reasons discussed in the previous section OBESITY it may be correlated with $\mu_{i t}$.

One may consider taking first-differences if one is willing to believe that $\mu_{i t}$ remains constant over time $\left(\mu_{i t}=\mu_{i}\right)$. This strategy was adopted by Baum and Ford (2004), Cawley (2004) and Cawley and Danziger (2005). However, this is only useful if the effect of obesity on wages does not vary by age, i.e. $\beta_{t}=\beta$. Under these assumptions, the first difference equation that should be 
estimated equals

$\ln W_{i t}-\ln W_{i t-1}=\left(O B E S I T Y_{i t}-O B E S I T Y_{i t-1}\right) \beta+\left(X_{i t}-X_{i t-1}\right) \gamma+\left(\epsilon_{i t}-\epsilon_{i t-1}\right)$.

An important condition for obtaining consistent estimates from a first-difference estimator is that current obesity should not be related to both current and past wage shocks $\epsilon_{i t}$ and $\epsilon_{i t-1}$. The latter may be the case if the type of nutrient intake depends on wages, for example when low income people have a higher demand for relatively cheap energy dense fattening food. Taking firstdifferences may thus solve some endogeneity problems, but the estimates may still suffer from reversed causality.

According to Cawley (2004) obesity may be affected by wages

$$
O B E S I T Y_{i t}=X_{i t} \delta+W_{i t} \alpha+Z_{i t} \phi+\nu_{i t}+\theta_{i t}
$$

where $Z_{i t}$ contains variables only affecting obesity, $\nu_{i t}$ captures genetic and non-genetic components and $\theta_{i t}$ contains shocks. There are potential sources for endogeneity bias of obesity in the wage equation (1). First, current wages $W_{i t}$ may affect current $O B E S I T Y_{i t}$. This reverse causality means that $\alpha$ in Equation (3) is non-zero. Second, $\mu_{i t}$ and $\nu_{i t}$ may be correlated, which implies that there are unobserved factors affecting both obesity and wages.

Identification of the causal effect of obesity on wages should come from independent variation in obesity status. In particular, the variable $Z_{i t}$ should have a non-trivial effect on obesity. If we use $Z_{i t}$ to instrument OBESITY in the levels equation (1), the identifying assumption is that $Z_{i t}$ should be uncorrelated to $\mu_{i t}$ and also to wage shocks $\epsilon_{i t}$ in the wage regression. Instead, we could focus on the first-difference equation (2) and instrument the change in obesity over time $\left(O B E S I T Y_{i t}-O B E S I T Y_{i t-1}\right)$. In particular, if $\alpha$ in equation (3) is non-zero, the change in obesity is related to the change in wage-shocks $\epsilon_{i t}-\epsilon_{i t-1}$. Since in the first-difference equation time-invariant factors are eliminated, less strong requirements are necessary for the validity of the instruments $Z_{i t}$. However, a few remarks should be made. First, the assumptions for validity of the instrumental variables are only relaxed if genetic and non-genetic factors are indeed time-invariant and thus no longer appear in equation (2). Second, either the instrumental variable should be timevarying itself or it should in levels have a non-trivial effect on $\left(O B E S I T Y_{i t}-\right.$ $\left.O B E S I T Y_{i t-1}\right)$. The latter is equivalent to replacing $\phi$ in equation (3) by $\phi_{t}$. As we will mention below our instrumental variables are indeed timeinvariant. This implies that when estimating the first difference equation (2) using instrumental variables estimation, the first-stage regression is

$$
\text { OBESITY } Y_{i t}-O B E S I T Y_{i t-1}=\left(X_{i t}-X_{i t-1}\right) \delta+Z_{i} \pi+\left(\theta_{i t}-\theta_{i t-1}\right) .
$$

where $\pi=\phi_{t}-\phi_{t-1}$. Third, as already discussed above taking first-differences is only useful if the effect of obesity on wages $\beta$ is the same over all ages. 
If $\beta$ would differ by age $t$, then both $O B E S I T Y_{i t-1}$ and $O B E S I T Y_{i t}$ would enter the first-difference equation as separate regressors instead of the regressor OBESITY $Y_{i t}-O B E S I T Y_{i t-1}$. Having OBESITY $Y_{i t-1}$ and OBESITY $Y_{i t}$ as separate regressors would be particularly problematic if the instrumental variables are time-invariant. In that case it would require finding two valid instrumental variables. The latter would not be necessary if we estimate the wage equation in levels where the effect of obesity on wages can vary with age.

We follow Cawley (2004) and use obesity status of biological relatives as instrumental variables. In particular, we use obesity of the parents of the respondent. It is well established, through twin, adoption, and family studies, that an individual's risk of obesity is greatly increased when he or she has relatives who are obese. A number of studies have provided evidence, suggesting that 40 to $70 \%$ of the variation in obesity-related phenotypes, such as body mass index, skinfold thickness, fat mass, and leptin levels, is inheritable.

The crucial assumption for parental obesity to be a valid instrument for the respondent's obesity is that it should not have an independent effect on the respondent's labor market outcomes. One could however think of a number of other pathways through which parental obesity could affect the respondent's labor market outcomes.

First, genetic factors determining weight may be the same, or are correlated with, genetic factors determining labor market success. In the estimations we include several variables correlated with parental labor market outcomes as regressors. These variables should control for such genetic factors, if they exist. Furthermore, estimating the model in first differences as in equation (2) may solve some of these issues as it removes time-invariant genetic effects from the wage regression. However, this specification requires instrumenting the change in respondent's obesity status. We show however that the association between child and parental obesity becomes stronger as the respondent becomes older. This would imply $\phi$ in equation (3) indeed depends on $t$. The underlying assumption here is that the growth in body mass will be faster in subjects with a genetic predisposition towards obesity. Figure 1 supports this claim, showing that the increase in obesity from age 23 and onwards seems to be greater for those having an obese mother.

Second, one could imagine the existence of household environment factors common to respondents and their parents that may affect both the respondent's wages and obesity. Cawley (2004) argues forcefully, however, that all correlation in weight between biological relatives is due to genetic factors and cites evidence from several studies, all pointing to the non-importance of such common household effects. It has been found, for instance, that the correlation between the body size of parents and their children is no different for twins reared apart or together (e.g. Maes et al. 1997). Moreover, it has been found that there is no significant correlation between the body mass of unrelated adoptees reared in the same family (Grilo and Pogue-Geile 1991). Reviewing the literature on genetic and environmental influences on obesity, Grilo and Pogue-Geile (1991) concluded that the only important environmental experi- 
ences are those not shared among family members and that experiences shared among family members appear largely irrelevant in determining individual differences in weight and obesity.

However, this is not uncontroversial. There is a strand of literature that argues that the family environment plays the main role in the development of children's food preferences. The idea is that parents shape the eating environment of their children by making food available and by their own eating habits and food choices (see Birch 1999, for a review). We have access to an exceptionally rich dataset that allow us to deal with this to some extent. The data has detailed information on parental choices regarding investments in their children's well-being and health such as, whether the child was breastfed, whether the parents took their child out for walks, outings, whether the parents went to swimming pools with their child and whether the mother and father read frequently to the child. Furthermore there is information on mother's smoking behavior during pregnancy, whether there were domestic tensions in the family and whether there were alcohol problems in the family. Such variables are likely to be strongly correlated to parental preferences towards food and eating habits. We will examine the sensitivity of our estimates to the inclusion of these parental input variables. Furthermore, it is not necessarily so that any non-genetic factors potentially reflected in the relationship in obesity between a parent and child renders the instrument invalid. If nongenetic eating preferences are transmitted from the parent to the child, this is no problem as long as these eating preferences are not directly related to the labor market outcomes of the child. It should also be noted that the food rationing implemented in Great Britain during the second world war did not end in until 1954, when the last restrictions on the sales of meat and bacon were lifted (Huxley et al. 2000). The parents of the NCDS respondents thus grew up in an environment with food rationing, where fatness could be expected to be more dependent on genetic factors than on excessive eating habits. Finally, our data has a subsample of adoptees. If environmental factors are important one would also expect to see an association in obesity between the adopted child and their adoptee parents.

\section{Data}

In the empirical analyses we will use data from the National Child Development Study (NCDS). The NCDS is a longitudinal study of about 17,000 individuals born in Great Britain in the week of March 3-9, 1958. Originally, the NCDS started out as the "Perinatal Mortality Survey", with the aim of surveying economic and obstetric factors associated with stillbirth and infant mortality. Since the first survey in 1958, cohort members have been traced on seven other occasions, in 1965 (age 7), 1969 (age 11), 1974 (age 16), 1981 (age 23), 1991 (age 33), 1999/2000 (age 42), and 2004 (age 46). It should be noted, however, that we do not use the information from the 2004 wave, since it does not 
include information on height and weight.

In the 1958 wave, information was gathered from the mother and from medical records, whereas interviews were carried out with parents, teachers, and the school health service in waves 1 to 3 . In the latter waves, ability tests were administered to the cohort members. In subsequent surveys, information on employment and income, health and health behavior, citizenship and values, relationships, parenting and housing, education and training of the respondents was included.

Since the NCDS is a long panel, attrition may be of serious concern. It should be noted, though, that Case et al. (2005) investigated attrition in the NCDS by comparing low birth weight and father's occupation across the different waves. No evidence for any non-random attrition with respect to these variables was obtained. Moreover, advisory and user support groups of the NCDS compared respondents and non-respondents in the later surveys in terms of social and economic status, education, health, housing and demography. Again, it was found that the sample survivors did not differ from the original sample to any great extent (National Child Development Study User Support 1991). In yet another study, the 1981 sample was compared to the United Kingdom 1981 Population Censuses in terms of key variables such as marital status, gender, economic activity, gross weekly pay, tenure and ethnicity (Ades 1983). The author concluded that the sample appeared to be representative with respect to these variables.

\subsection{Dependent variable: labor market outcomes}

Our two main dependent variables are employment and wages. We consider employment at age 42, defined as having a full-time or part-time job, or being self-employed. We construct a measure of the gross hourly wage rate at age 42 by using information on payment intervals, actual payment, and hours worked. First the individual was asked to state in which intervals he/she was paid. Second, it was asked how much the gross amount was, excluding any overtime. Third, information was given on the weekly number of contractual hours of work, excluding any overtime hours. From this information we calculated the hourly gross wage. ${ }^{1}$

\subsection{Independent variables}

\subsubsection{Obesity status}

The NCDS records the height and weight of the respondents at all waves, except for the last one in 2004. In the 1981 and 2000 waves, weight and height were self-reported, while they were measured by interviewers in the other waves. Using the measures on height and weight, we construct a measure

\footnotetext{
${ }^{1}$ We excluded observations with a hourly wage rate below the minimum wage of $£ 3.60$ and above $£ 100$, resulting in a loss of 219 observations.
} 
of Body Mass Index (BMI), which, in turn, is used to construct an indicator of being obese. We follow the convention and label someone as obese if having a BMI of 30 or above. Since the definition of obesity varies for children and teenagers, we use age-specific tresholds of obesity and overweight, as provided by Cole et al. (2000).

Previous research has shown substantial measurement errors in self-reported height and weight (e.g. Rowland 1989). For instance, underweight people tend to overreport their weight, while the opposite is the case for overweight people. We correct for such errors in self-reported height and weight in the 1981 and 2000 waves by using the results from Burkhauser and Cawley (2008), where prediction equations for actual weight and height were provided. Applying their formulas, average BMI for females at age 42 increase from 25.29 to 25.68 and from 26.58 to 26.75 for males. This, in turn, increases the fraction of obese females from $15.1 \%$ to $16.9 \%$ and the fraction of obese males from $15.7 \%$ to $16.7 \%$. It should be noted that the correction for systematic measurement error might be more important in OLS regressions than in regressions in which obesity is instrumented. It is well known that classical measurement errors in regressors cause OLS estimates to be biased towards 0 , which can be solved by instrumenting the regressors. Descriptive statistics on obesity status are shown in Table 1.

The NCDS also includes information on the weight and height of the respondent's father and mother. This information was assessed in wave 3 , when the respondents were 11 years old, and is self-reported by the mother and father. Since we are mainly interested in the obesity of a biological parent, we make use of information on family relations, allowing us to discriminate between biological parents and adoptee parents, step parents, and foster parents. In the empirical analyses we only focus on individuals for which both the father's and mother's obesity status are recorded at age 11.

Figure 1 shows obesity rates at various ages by the obesity status of the mother and the father for the NCDS respondents Clearly, the obesity rates are greater for those having an obese mother or father at all ages considered. At age 7 , the obesity rate of those with obese parents is about twice as high as for those with non-obese parents. At ages 11 and 16 the difference becomes even greater. From age 23 and onwards, the picture suggest that the increase in obesity is greater for those having obese parents. However, it should be noted that the dip in obesity at age 23 is also greater for those with obese parents. This dip may suggest that the self-reports on height and weight at age 23 are unreliable and that our measurement error correction does not address this adequately. In the following, we will therefore not use information on obesity at age 23. Another reason for not using the data at age 23 is that at this age some individuals were still in full-time education. At age 42 , which is the age at which we evaluate labor market outcomes, the obesity rate of those having obese parents is about 33 percent, whereas the corresponding rate for those not having obese parents is about 15 percent. The figure suggest that there are substantial differences in the probability of being obese by the obesity 
status of the parents. This also gives us the predictive power needed from our instrument.

\subsubsection{Other background variables}

The National Child Development Study contains rich information on issues such as the individual's initial health assets, the socioeconomic status during early childhood, and cognitive ability during childhood. We follow Llena Nozal (2007) and Case et al. (2005) when constructing our relevant background variables. In Table 1, sample means are shown. Since many variables have some item non-response, we follow Case et al. (2005) and construct dummy variables that indicate if the information on a variable is missing, in order to avoid losing many observations.

In order to measure the family's socioeconomic status, we include information on the number of years of education of the mother and the father, a measure of permanent family income at age 16, and a measure of financial problems in the family at ages 11,14 , and 16 .

As to family income, the NCDS only records it when the child is 16 . Since this measure might not reflect living standards earlier in childhood or persistent poverty problems, the data holders have developed a measure of family income, which we will make use of. Since the permanent income measure is dependent on the estimation technique and data availability, however, we will use this measure in combination with the measures of whether or not the family had serious financial difficulties when the child was aged 7, 11, and 16 .

We created a number of different measures of parental inputs and early life conditions. In order to capture mother's smoking during pregnancy, we created a dummy variable indicating if the mother smoked after the fourth month of pregnancy. Smoking during pregnancy has been found to be related with cognitive deficiencies and other health problems, such as low birth-weight, and may thereby affect both obesity and labor market outcomes (see for instance Blair et al. 1996; and Williams et al. 1998). Moreover, the mother's age at the child's birth may affect child's health through, for instance, nutritional deficiencies if the mother is very young, or delivery complications if the mother is older (Llena Nozal 2007). In addition, we include an indicator of having low birth weight and whether the respondent was breastfed.

A number of indicators of parental activities together with their child was created as well. These indicated whether the mother or the father often took the child for walks, to swimming pools, to outings and were assessed when the child was 11 . In addition, we constructed variables indicating whether the mother and the father frequently did read books to the respondent at age 7 . Finally, two variables measuring the presence of any alcohol problems among the parents and the presence of any domestic tension during the upbringing of the child were created.

To measure cognitive ability at early ages, we used the results from test scores on math and reading tests at ages 7 and 11. In the math test, which 
was designed for the National Child Development Study, the score ranges from 0 to 10. Prior studies have established that test scores at the age of 7 show a significant impact on later education attainments and labor market outcomes (Currie and Thomas 2001). Reading skills were assessed by the Southgate Reading Test.

Social maladjustement was assessed at ages 7 and 11 with The Bristol Social Adjustment Guide (BSAG) study. The BSAG consists of a large number of behavioral items, such as 'attitudes to teacher', 'attitudes towards other children', evaluated by the child's teacher. Higher scores indicate higher maladjustment.

Education is measured through 4 dummy variables, indicating national vocational qualification levels. The following categories were included: less than O-levels, O-level equivalent, A-level equivalent, and degree equivalent. This follows the definition used by Llena Nozal (2007). To capture marital status, we created a dummy variable indicating if the respondent was married or cohabitating. Ethnicity was measured through a dummy variable, indicating if the respondent belonged to the European Caucasian, group. Additional covariates were the number of children and the number of cigarettes smoked per day.

\section{Results}

\subsection{Baseline OLS Results}

We start by examining whether there exist any evidence suggesting different labor market outcomes by obesity status in our data. Table 2 summarizes the results from regressions on the association between obesity and employment and wages at age 42 . The first column of the tables shows the results when we include only the individual's obesity status as covariate. In columns (II) to (V) we then add various sets of control variables. It should be noted that the results in the different rows reflect separate regressions on the effect of obesity at various ages on the outcomes at age 42 .

Starting with only obesity as covariate (columns (I)) the results show that obesity measured at age 33 is significantly and negatively related to wages for males. Obese males face an wage penalty of $7.8 \%$. For females, both obesity measured at 33 and 42 shows a negative and significant association with wages. The obesity penalty is twice as large when obesity is measured at age $33,11.5 \%$, as when measured at age 42 . Recall that at age 42 height and weight were self-reported, which might yield measurement errors which downward bias the estimated coefficient.

Table 2 also reveals that both obese males and females face significantly lower employment probabilities. Being obese at age 42 is associated with a 4.9 percentage points reduction in the employment probability for females and a 2.3 percentage points reduction for males. Even stronger results are obtained 
when measuring obesity at age 33, with the obesity penalty doubling for males and increasing by about $20 \%$ for females.

\subsection{Accounting for heterogeneity}

\subsubsection{Controlling for socioeconomic characteristics}

The results discussed so far did not control for other characteristics of the individual that may be correlated with obesity. In the columns (II) of Table 2 , we therefore add some basic control variables, including marital status, ethnicity, education, number of children, and smoking. For males, this renders the obesity wage penalty insignificant and close to zero. For females, the obesity wage penalty is reduced to half when obesity is measured at age 33 and becomes insignificant when measuring obesity at age 42. Adding these basic control variables has less of an effect on the association between obesity and employment. The associations are still significant for both males and females, although they are somewhat reduced in magnitude.

\subsubsection{The influence of family background}

Obese persons may come from other types of family backgrounds than their non-obese counterparts. Coming from a background with lower economicand human capital, for instance, may also affect later labor market outcomes. Thus, the previously found employment "gap" by obesity status may simply reflect such differences. In order to account for differences in family background, we include controls for parental education, permanent income, and financial difficulties in the household at ages 7,11 , and 16 . The results are shown in the columns (III) of Table 2.

The association between obesity and wages for females, when obesity is measured at age 33, is only slightly affected when controlling for family background. The wage penalty is now $5.6 \%$ and only significant at the $10 \%$ level. For males, it remains small and insignificant. Moreover, few of the parental background variables (not shown) show any significant association with wages, the exception being the parents having financial difficulties at age 7 and 16 for males (results available on request). This suggest that these differences in

family background between obese and non-obese people explain little of the difference in labor market outcomes between the groups.

For employment, the association with obesity does not change to any important extent when controlling for family background. The exception is obesity measured at age 42 for males, which is no longer significantly related to employment.

\subsubsection{What role does cognitive ability play?}

There may still be other important differences between obese and non-obese people that we have not accounted for. One may suspect that obesity is 
simply picking up some differences in cognitive ability between the obese and non-obese. We therefore add controls for cognitive ability, measured through results on test scores in math and reading at ages 7 and 11. In addition, we control for social maladjustment at ages 7 and 11. The results are shown in the columns (IV) of Table 2 . The addition of cognitive ability does not change the results for wages and has only a slight effect on the employment estimates. For males, the employment penalty obtained when obesity is measured at age 33 is now reduced in magnitude and is only significant at the $10 \%$ level.

\subsubsection{Is it the parental inputs?}

Finally, we consider the importance of a number of parental inputs, that may not have been picked up by the family background variables. Here, we consider leisure activities, such as taking the child frequently for walks, to swimming pools, and on outings at age 11. Moreover, we include controls for parental educational inputs, measured through whether the mother and the father read frequently to the child. Finally, we control for mothers smoking during pregnancy, whether or not the mother breastfeeded, the existence of alcohol problems within the family, low birth weight, and the existence of any domestic tension within the household.

As seen in the columns (V) of Table 2, the associations between obesity and wages and employment does hardly change. It should also be noted that very few of these early parental inputs show any significant effect on later labor market outcomes (results on request). In sum, differences in family background, cognitive ability, and parental inputs by obesity status does not seem to fully explain why obese people fare worse on the labor market at later ages.

\subsection{Instrumental variable estimation}

Even though the richness of the NCDS data allow us to control for many previously unmeasured factors, such as cognitive abilities and parental investments, important factors may still remain unmeasured. Moreover, as previously discussed, reverse causality running from labor market outcomes to obesity and BMI may bias our results. We will therefore resort to instrumental variables estimation, using as instrument our indicator of the obesity status of the mother and the father of the respondent.

\subsubsection{Parent-child association in obesity and the role of family background}

First, we will examine to what extent the association in obesity between the parent and the child is affected when accounting for non-genetic factors pertaining to the family background of the child. If the association in obesity is unaffected when accounting for potentially important environmental influences 
during childhood and adolescence, this provides at least suggestive evidence that the association is mainly due to genetic factors.

In the first four columns of Table 3, the raw parent-child association in obesity at various ages are shown, separately for females and males and for mothers and fathers. Each row thus represents a separate regression Clearly, there is a strong association in obesity between the parent and the child at all ages, for both males and females. The associations tend to be stronger at older ages, which is not that surprising, since at these ages, the main respondent is closer to the age at which the height and weight of the mother and the father were assessed.

In columns five to eight of Table 3, the same associations are again examined but this time controlling for all observed demographic, socioeconomic, environmental and behavioral characteristics described in the preceding section. The results show that the parent-child association remains very similar. Moreover, most of the included control variables are not significant in explaining obesity at later ages (results available on request). This is in line with the results from previous studies, suggesting that the association in obesity between biological relatives is mainly due to genetic factors and that factors related to a common environment plays a small or no role.

\subsubsection{Is the mother-child relationship in obesity different for adopted children?}

Next, we turn our attention to differences in the parent-child association in obesity between adopted and non-adopted children. The NCDS records whether the main respondent was adopted. If the parent-child association is only due to genetics, we would expect no relationship in the obesity status of adopted children and their adoptee parents. For the analysis to make sense, we must first make sure that the allocation of adopted children is made in a close to random manner. For the NCDS this has been established by Sacerdote (2000).

The sample of adopted children is small, only 79, and the results are therefore not likely to be very strong. Yet, they may provide at least some suggestive evidence, pointing in the same direction as our previous results. We will therefore run regressions, pooling the samples of adopted and natural children and include interaction terms between the dummy variable indicating not being an adopted child and the variable measuring the obesity status of the parent. If the parent-child association is due to genetics, we would expect the interaction effects to be positive, but the main effect, measuring the relationship for adopted children, to be close to zero or negative for adopted children.

To maximize the number of adopted children, we will only consider the respondents at ages 7,11 , and 16. At later ages, due to attrition, the sample of adopted children becomes very small. The early ages are the most relevant since this is the period where most children and parents share a common environment. 
In Table 4 OLS results for the full sample at the ages 7, 11, and 16 are shown. The table shows the coefficients of the variables indicating parental obesity, the dummy variables indicating not being an adopted child, and the interaction terms between the former and the latter variables. ${ }^{2}$ The results show that the interaction terms are positive at ages 7,11 , and 16 . The magnitude of the main effect of mother's and father's obesity suggests an association that is either close to zero or negative for adopted children. This is found for all the ages considered in the analysis. This is in line with what we would expect if genetics play the major role for the association in obesity between parents and children. The sample of adopted children is small, however, and the interaction effects never reach statistical significance. We are therefore not able to draw any firm conclusions from this exercise, but we note that the results at least points to the direction of no association or a negative association in obesity between adopted children and their adoptee parents.

The exercises above, together with the evidence from previous twin and adoption studies, gives some credibility to the claim that the obesity of a parents predicts genetically induced variation in the obesity of the child. If true, non-genetic factors that are common to the child and the parent play little role for obesity, meaning also that those factors do not predict both obesity and labor market success, which would invalidate our instrument.

\subsubsection{IV-results}

Next, we perform instrumental variables analyses. The results are summarized in Table 5. To preserve space, we only show the marginal effects of the obesity variable. For males, the results now show a negative, but insignificant association between obesity at ages 42 and 33 and wages. The point estimates suggest a wage penalty between $27 \%$ and $31 \%$. The first stage regressions reveal no problem of weak instruments, with F-statistic in all cases well exceeding 10. The tests for our exclusion restrictions, however, suggest that we may have a problem. For obesity measured at age 33, the p-value of the Sargan test statistic is 0.03 , casting serious doubts on using parental obesity as an instrument. Measuring obesity at age 42 , the corresponding p-value is 0.10 , which is lower than we would prefer.

For females, the estimates suggest a wage penalty of obesity between $5 \%$ and $9 \%$. These point estimates are again not significant however. The instruments again appear strong, with F-statistics exceeding 10 in the first stage regressions. Again, however, our exclusion restrictions are called into doubt, as the p-value of the Sargan test statistic is 0.05 , when measuring obesity at age 33 .

For employment, the IV estimates are very different from the OLS estimates. For males, the association between obesity and employment is now

\footnotetext{
${ }^{2}$ We ran the analysis both with and without controls for parental background and environmental influences but the results were similar. The results presented in Table 4 are without controls.
} 
positive but imprecisely measured and insignificant. The instruments predicts well, with F-statistics above 10 in the first-stage regressions. Similar results are found for females, where the coefficients of obesity at various ages are now positive and insignificant. The previously found negative and significant association between obesity and employment of women has now completely vanished. Also among women, the instruments predicts obesity well. While we cannot exclude that our exclusion restrictions are valid in the employment regressions, based on the Sargan test, it should be noted that the p-values are rather low in two out of the four specifications.

\subsection{Changes in obesity and employment}

If the genes that determine obesity are the same or are correlated with the genes that determine employment, both our OLS and IV-estimates may still be biased. To the extent that cognitive ability, for instance, is genetically determined it is certainly not farfetched to assume that both employment and obesity may be affected by it. In the case of cognitive ability, we are able to control for it by including education and test scores at childhood, but for other potentially genetically determined characteristics we may be less successful.

We therefore next utilize the panel feature of the NCDS in order to examine changes in employment status and obesity between the waves. We do not consider changes in wages, since the data on these outcomes in the 1991 wave do not seem comparable to the data of 2000. Estimating our regressions in first differences, we are able to remove some of the unobserved heterogeneity that may plague both the OLS and IV estimates. While only time-invariant unobserved heterogeneity will cancel out, it should be noted that some of the important unmeasured factors in our case are indeed time-invariant, such as genetic upset.

Table 6 shows the results from the first-difference equation. In this specification, we are analyzing changes in employment between age 42 and 33 as a function of changes in obesity between ages 42 and 33. In our sample of males, $9 \%$ changes employment status across the waves. The corresponding percentage of females is $30 \%$. Since most of the control variables are constant over time, they will drop out from the analysis, but we allow for changes in marital status and in smoking. For males, the results show a slight positive association between changes in obesity and employment that is significant at the $10 \%$ level. For females, the association is negative but not significant.

While first-difference estimation removes time constant unobserved heterogeneity, and thereby helps us reduce the influence of common genes affecting obesity and employment, there still exists the possibility that reverse causality biases the results. Employment shocks at an earlier period could still affect obesity status, for instance. This may for instance explain the positive association between obesity and employment found when using first-differences. Next, we therefore instrument the change in obesity with the obesity status of the mother and the father. The argument for our instrument is basically 
similar as before, i.e. that the obesity status of the parent predict genetic variation in obesity in the child. The only difference is that we now hypothesize that the growth in obesity will be faster in subjects with a genetic predisposition towards obesity. Since all time-invariant factors are washed out in this specifications, we assume that the effect of any obesity genes transmitted from the mother/father may change over time. The notion that the association in the obesity status of the child and the parent may change over time, which may partly be due the effect of genes being different at different ages, was supported by the results in Table 3 . In this case, we could instrument any time-variant effect of these genes with the obesity of the parents, as discussed in Section 2.

For males, the first-difference IV-estimate, shown in the third column of Table 6 , is negative but not significant. For females, the coefficient is positive but imprecisely measured. The results for both females and males suffer from a weak instrument problem, however, as the F-statistics from the first-stage regressions are below 10 in both cases. Thus, in this case it does not help much that the tests for exclusion restrictions are passed and we must consider the results to be unreliable.

\section{Discussion and conclusions}

If obesity has a causal effect on labor market success, there may be large gains at both the individual and societal level from more efficient obesity treatments. Indeed, previous studies have suggested relatively large penalties from being obese. If obesity is simply picking up some other, unmeasured trait, treatments and/or policies aimed at reducing obesity will not have the intended effects on labor market outcomes. It is therefore of great importance to increase the knowledge about the causal effect of obesity on labor market success.

In this paper, we started by showing that there exist differences in employment probabilities between obese and non-obese men and women. We also showed that these differences did not disappear when controlling for a wealth of potentially important factors pertaining to family background, cognitive ability, and inputs during childhood and adolescence. For wages, the results suggested that obese females face a wage penalty on the labor market. The results may however reflect associations rather than causal effects.

We next utilized the fact that the NCDS includes information on the obesity status of the respondent's mother and father. In order to assess the validity of the instruments, we conducted a number of tests. These tests suggest that it is mainly genetic variation which causes intergenerational correlation in obesity, while environmental factors play less of a role. Using our instruments, negative but insignificant associations between wages and obesity were obtained for both men and women. For employment, the point estimates were positive but insignificant for both men and women. However, we are doubtful about the validity of our instruments since they did not pass the tests for overi- 
dentifying restrictions in several specifications. The failure of the tests may suggest that our instruments were still picking up the influence of unobserved factors that were correlated with both obesity and labor market outcomes.

We also utilized the panel feature of the NCDS and conducted regressions in first differences on employment. With this strategy, we removed unmeasured, time invariant, heterogeneity, such as the influence of common genes. In this specification, a positive association between obesity and employment for men, significant at the $10 \%$ level, was obtained while a negative and insignificant association was obtained for women. Since we were concerned that reverse causality, running from employment to obesity, was biasing these first difference results, we conducted first-difference instrumental variables estimation. Instrumenting the change in obesity with the parents' obesity in levels, we found no significant relationship between obesity employment. However, these estimates suffered from a weak instruments problem.

In sum, we remain sceptical about the use of the body mass of a biological relative as an instrument, as first proposed by Cawley (2004). Future research should look for other ways to address the endogeneity of obesity, when studying its association with labor market outcomes.

\section{References}

Abbott RD, Behrens GR, Sharp DS, Rodriguez BL, Burchfield CM, Ross GW, Yano K, Curb JD (1994). Body Mass Index and Thromboembolic Stroke in Non-smoking Men in Older Middle Age. The Honolulu Heart program. Stroke 25: 2370-2376.

Ades T (1983). Comparing National Child Development Study4 to the 1981 United Kingdom Census. National Children's Bureau, National Child Development Studies Working Paper, Fourth Follow-up: No. Paper 11.

Baum II CL, Ford WF (2004). The Wage Effects of Obesity: a Longitudinal Study. Health Economics 13: 885-899.

Birch LL (1999). Development and Food Preferences. Annual Review of Nutrition 19: 41-62.

Blair, PS, Fleming PJ, Bensley D, Smith I, Bacon C, Taylor E, Gloding J, Tripp J (1996). Smoking and the sudden infant death syndrome: results from 1993-5 case-control study for confidential inquiry into stillbirths and deaths in infancy. British Medical Journal 313: 195-198.

Burkhauser R, Cawley J (2008). Beyond BMI: The value of more accurate measures of fatness and obesity in social science research. Journal of Health Economics 27: 519-529.

Case A, Fertig A, Paxson C (2005). The lasting impact of childhood health and circumstance. Journal of Health Economics 24: 365-389. 
Cawley J (2000). Body Weight and Women's Labor Market Outcomes. Working Paper 7841, NBER Working Paper Series.

Cawley J (2004). The Impact of Obesity on Wages. Journal of Human Resources 39: 451-474.

Cawley J, Danziger S (2005). Morbid Obesity and the Transition from Welfare to Work. Journal of Policy Analysis and Management 24: 727-743.

Cole TJ, Bellizzzi MC, Flegal MK, Dietz WH (2000). Establishing a standard definition for child overweight and obesity worldwide international survey. British Medical Journal 320: 1240-1243.

Currie J, Thomas D (2001). Early Test Scores, Socioeconomic Status and Future Outcomes. Research in Labor Economics 20: 103-132.

Grilo CM, Pogue-Geile MF (1991). The Nature of Environmental In uences on Weight and Obesity: A Behavioral Genetic Analysis. Psychological Bulletin 110(3):520-37.

Hamermesh DS, Biddle JE (1994). Beauty and the Labor Market. American Economic Review 84: 1174-1194.

Huxley RR, Lloyd BB, Goldacre M, Neil, HAW. (2000) Nutritional research in World War 2: The Oxford Nutrition Survey and its research potential 50 years later. British Journal of Nutrition 84, 247-251.

Kantarevic J, and Mechoulan S (2006). Birth Order, Educational Attainment, and Earnings: An Investigation Using the PSID. Journal of Human Resources 41, 755-777.

Llena Nozal A (2007). On the Dynamics of Health, Work and Socioeconomic Status. Dissertation. VU University Amsterdam.

Lundborg P, Lindgren B, Höjgård S, Bolin K (2007). Obesity and occupational attainment among the 50+ of Europe. In: Bolin K, Cawley J(eds.). Advances in health economics and health services research Volume 17: The Economics of Obesity. New York: Elsevier.

Maes HHM, Neale MC, Eaves LJ (1997). Genetic and Environmental Factors in Relative Body Weight and Human Adiposity. Behavior Genetics 27(4):325-51.

Mueller G, Plug E. (2006). Estimating the Effect of Personality on MaleFemale Earnings. Industrial and Labor Relations Review 59. Forthcoming.

National Child Development Study User Support Group (1991). National Child Development Study Report. City University: London.

OECD (2005). "Health at a Glance: OECD Indicators 2005. OECD Publishing.

Pi-Sunyer FX (2002). The obesity epidemic: pathophysiology and consequences of obesity. Obesity Research 10: 97-104. 
Puhl R, Brownell K (2001). Bias, discrimination, and obesity. Obesity Research 9: 788-805.

Rooth D (2009). Obesity, attractiveness and differential treatment in hiring a field experiment. Journal of Human Resources, forthcoming.

Rowland ML (1989). Reporting Bias in Height and Weight Data. Statistical Bulletin 70(2): 2-11.

Sacerdote B (2000). The Nature and Nurture of Economic Outcomes. NBER working paper 7949 .

Sobal J (2004). Sociological analysis of the stigmatisation of obesity. In Germov, J., Williams, L. (eds) A Sociology of Food and Nutrition: The Social Appetite. 2nd edition. John Wiley, Melbourne.

Williams GM, O'Callaghan M, Najman JM, Bor W, Andersen MJ, Richards D, Chinlyn U. (1998). Maternal Cigarette Smoking and Child Psychiatric Morbidity: A Longitudinal Study. Pediatrics 10211. 
Figure 1: Obesity status at various ages by parental obesity status.

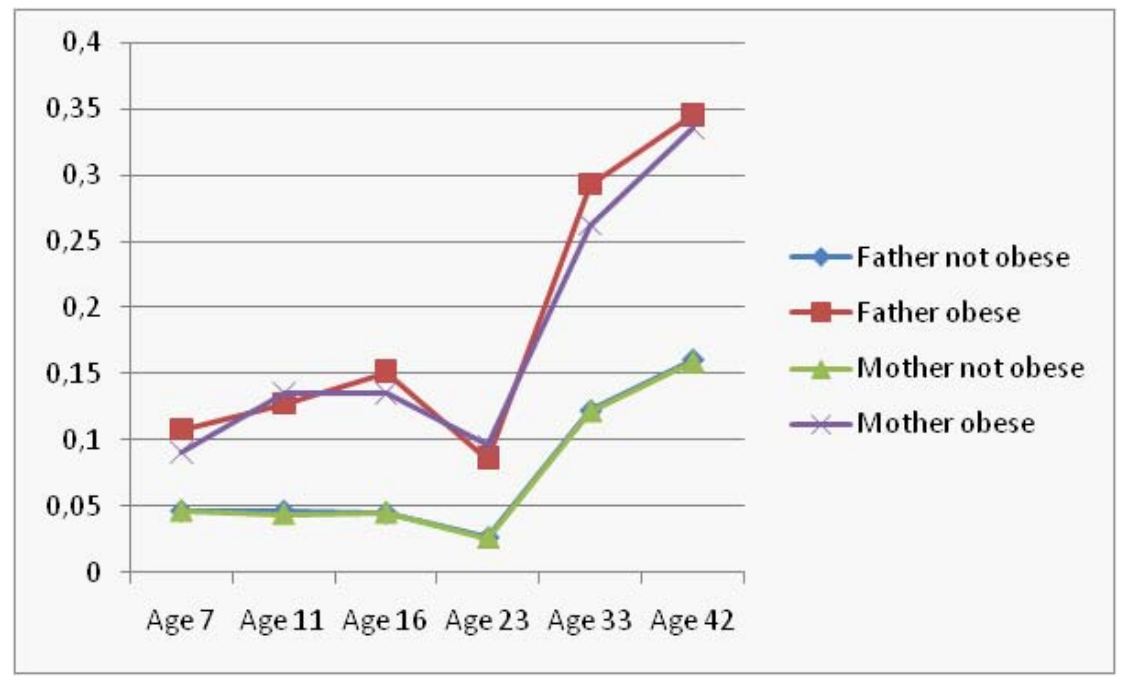

Figure 2: 
Table 1: Descriptive statistics.

\begin{tabular}{lcccc}
\hline \hline & Males & \multicolumn{3}{c}{ Females } \\
\cline { 2 - 5 } & Mean & SD & Mean & SD \\
\hline Dependent variables & & & & \\
Employed at age 42 & 0.916 & 0.277 & 0.798 & 0.401 \\
Employed at age 33 & 0.924 & 0.265 & 0.685 & 0.465 \\
ln(wage) at age 42 & 2.432 & 0.618 & 2.011 & 0.587 \\
& & & & \\
Obesity & & & & \\
Obese 42 & 0.167 & 0.373 & 0.169 & 0.375 \\
Obese 33 & 0.113 & 0.316 & 0.115 & 0.319 \\
Mother obese & 0.039 & 0.195 & 0.039 & 0.194 \\
Father obese & 0.069 & 0.254 & 0.060 & 0.237 \\
& & & & \\
Demographic variables & & & & \\
Less than O-level & 0.228 & 0.420 & 0.238 & 0.426 \\
O-level equivalent & 0.189 & 0.391 & 0.281 & 0.450 \\
A-level equivalent & 0.299 & 0.458 & 0.263 & 0.440 \\
Degree equivalent & 0.133 & 0.339 & 0.110 & 0.313 \\
White & 0.920 & 0.271 & 0.923 & 0.266 \\
Married or cohabitating & 0.806 & 0.396 & 0.810 & 0.392 \\
Father's years of schooling & 7.502 & 4.510 & 7.530 & 4.490 \\
Mother's years of schooling & 7.592 & 4.384 & 7.655 & 4.397 \\
Number of children & 1.468 & 1.349 & 1.763 & 1.364 \\
& & & & \\
Early life conditions & & & & \\
Mother's age at birth & 26.543 & 7.521 & 26.536 & 7.624 \\
Financial difficulties at age 7 & 0.040 & 0.195 & 0.053 & 0.224 \\
Financial difficulties at age 11 & 0.078 & 0.268 & 0.086 & 0.281 \\
Financial difficulties at age 16 & 0.063 & 0.243 & 0.063 & 0.244 \\
Domestic tension in family & 0.027 & 0.163 & 0.032 & 0.176 \\
Parental alcohol problems & 0.005 & 0.071 & 0.005 & 0.071 \\
\hline
\end{tabular}


Table 1: (Continued).

\begin{tabular}{lllll}
\hline \hline & Males & \multicolumn{3}{c}{ Females } \\
\cline { 2 - 5 } & Mean & SD & Mean & SD \\
\hline Parental investments & & & & \\
Mother smoked during pregnancy & 0.299 & 0.458 & 0.316 & 0.465 \\
Mother breastfeeded & 0.642 & 0.479 & 0.658 & 0.474 \\
Mother read & 0.464 & 0.499 & 0.457 & 0.498 \\
Father read & 0.337 & 0.473 & 0.338 & 0.473 \\
Often walked with mother (age 11) & 0.520 & 0.500 & 0.577 & 0.494 \\
Often walked with father (age 11) & 0.515 & 0.500 & 0.520 & 0.500 \\
Often went swimming with parents (age 11) & 0.443 & 0.497 & 0.468 & 0.499 \\
Outings with mother (age 7) & 0.778 & 0.416 & 0.803 & 0.398 \\
Outings with father (age 7) & 0.674 & 0.469 & 0.655 & 0.475 \\
Low birth weight & 0.080 & 0.272 & 0.103 & 0.304 \\
& & & & \\
Cognitive ability & & & & \\
Math score (age 7) & 4.990 & 2.796 & 4.857 & 2.685 \\
Math score (age 11) & 17.221 & 11.110 & 16.622 & 10.480 \\
Reading score (age 7) & 21.431 & 9.172 & 23.391 & 8.635 \\
Reading score (age 11) & 15.693 & 7.342 & 15.644 & 6.896 \\
BSAG score (age 7) & 8.282 & 8.679 & 6.205 & 7.445 \\
BSAG score (age 11) & 8.178 & 9.026 & 5.711 & 7.158 \\
& & & & \\
Other & & & & \\
Number of cigarettes & 4.486 & 9.145 & 3.898 & 7.844 \\
\hline
\end{tabular}




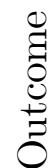

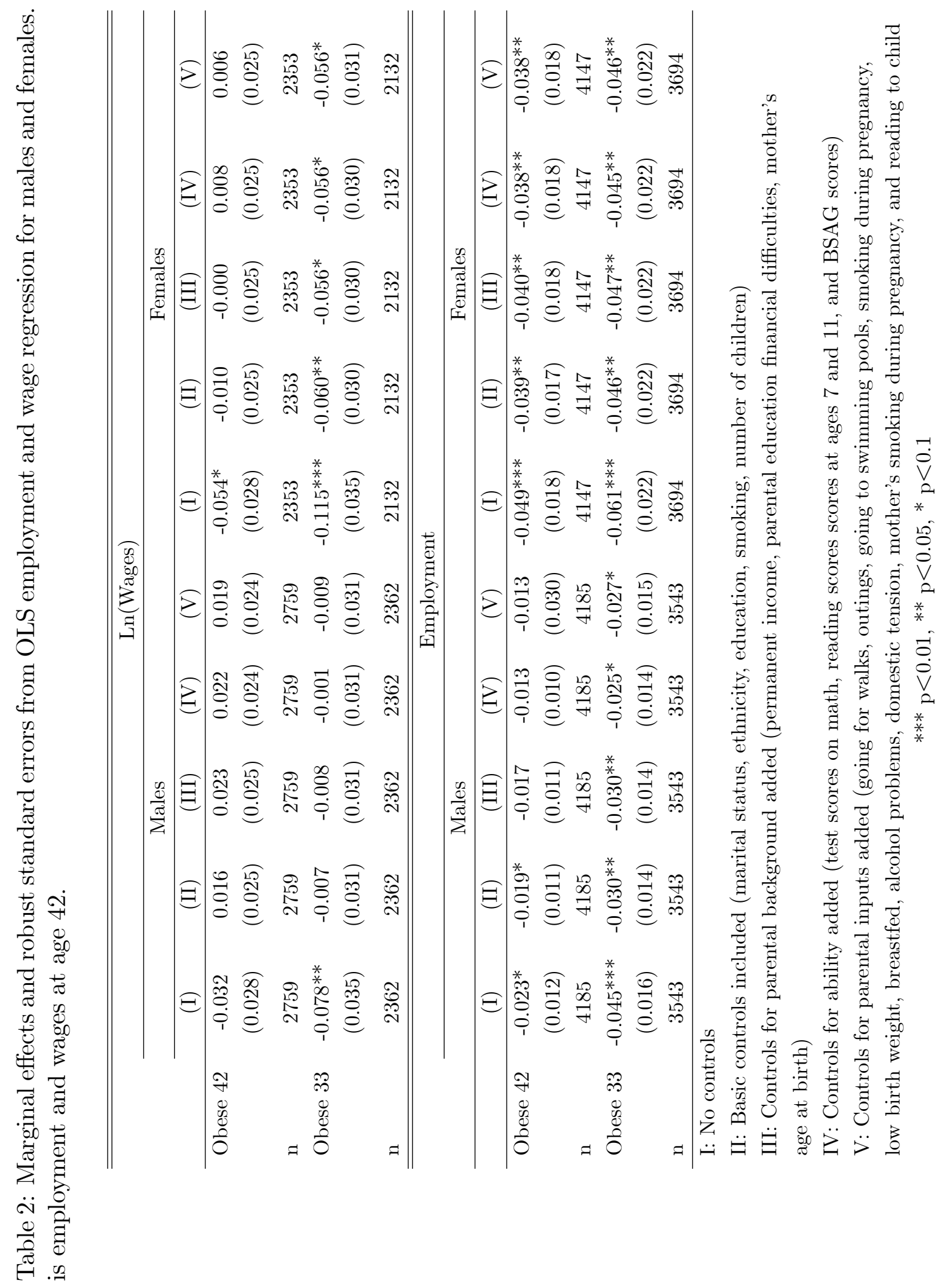


Table 3: Correlation in obesity status between the child and the child's mother and father.

\begin{tabular}{ccccccccc}
\hline \hline \multicolumn{4}{c}{ (I) Raw association } & \multicolumn{3}{c}{ (II) Association with controls } \\
\hline & \multicolumn{2}{c}{ Males } & \multicolumn{2}{c}{ Females } & \multicolumn{2}{c}{ Males } & \multicolumn{2}{c}{ Females } \\
\cline { 2 - 9 } & Mother & Father & Mother & Father & Mother & Father & Mother & Father \\
\hline Age 7 & $0.0120^{*}$ & $0.0426^{* * *}$ & $0.0477^{* * *}$ & $0.0285^{* *}$ & $0.0126^{* *}$ & $0.0438^{* * *}$ & $0.0498^{* * *}$ & $0.0279^{* *}$ \\
Age 11 & $0.0420^{* * *}$ & $0.0358^{* * *}$ & $0.0413^{* * *}$ & $0.0299^{* * *}$ & $0.0419^{* * *}$ & $0.0362^{* * *}$ & $0.0403^{* * *}$ & $0.0292^{* * *}$ \\
Age 16 & $0.0280^{* * *}$ & $0.0325^{* * *}$ & $0.0459^{* * *}$ & $0.0486^{* * *}$ & $0.0255^{* * *}$ & $0.0306^{* * *}$ & $0.0466^{* * *}$ & $0.0449^{* * *}$ \\
Age 23 & $0.0297^{* * *}$ & $0.0634^{* * *}$ & $0.101^{* * *}$ & $0.0328^{* *}$ & $0.0252^{* * *}$ & $0.0593^{* * *}$ & $0.0941^{* * *}$ & $0.0290^{* *}$ \\
Age 33 & $0.0591^{* * *}$ & $0.199^{* * *}$ & $0.151^{* * *}$ & $0.108^{* * *}$ & $0.0437^{* *}$ & $0.192^{* * *}$ & $0.133^{* * *}$ & $0.0978^{* * *}$ \\
Age 42 & $0.131^{* * *}$ & $0.187^{* * *}$ & $0.193^{* * *}$ & $0.140^{* * *}$ & $0.124^{* * *}$ & $0.176^{* * *}$ & $0.165^{* * *}$ & $0.128^{* * *}$ \\
\hline
\end{tabular}

(II) Basic controls, parental background, cognitive ability, and parental inputs

$* * * \mathrm{p}<0.01,{ }^{* *} \mathrm{p}<0.05,{ }^{*} \mathrm{p}<0.1$ 
Table 4: Correlation in body size between adopted and biological children obesity status and the parents obesity status.

\begin{tabular}{lccc}
\hline \hline & \multicolumn{3}{c}{ Ages } \\
\cline { 2 - 4 } & Age 7 & Age 11 & Age 16 \\
\hline Mother obese & -0.0171 & -0.0292 & -0.0194 \\
Father obese & $(0.082)$ & $(0.065)$ & $(0.12)$ \\
& -0.0211 & -0.0281 & -0.00989 \\
Non-adopted (mother) & $(0.081)$ & $(0.074)$ & $(0.085)$ \\
& 0.0121 & -0.00307 & -0.0191 \\
Non-Adopted (father) & $(0.029)$ & $(0.025)$ & $(0.028)$ \\
& -0.0130 & -0.0137 & 0.00975 \\
Non-Adopted(mother)*mother obese & 0.0448 & 0.0707 & 0.0574 \\
& $(0.082)$ & $(0.065)$ & $(0.12)$ \\
Non-Adopted(father)*father obese & 0.0563 & 0.0582 & 0.0514 \\
& $(0.081)$ & $(0.074)$ & $(0.085)$ \\
Observations & 10565 & 11487 & 8827 \\
$R^{2}$ & 0.01 & 0.01 & 0.01 \\
\hline
\end{tabular}

Robust standard errors in parentheses

$$
\text { *** } \mathrm{p}<0.01,{ }^{* *} \mathrm{p}<0.05,{ }^{*} \mathrm{p}<0.1
$$


Table 5: Marginal effects and standard errors from IV wage regression and IV employment regression for males and females.

\begin{tabular}{lcccc}
\hline \hline & \multicolumn{2}{c}{ Wages } & \multicolumn{2}{c}{ Employment } \\
\cline { 2 - 5 } & Males & Females & Males & Females \\
\hline Obese 42 & -0.309 & -0.046 & 0.113 & 0.014 \\
& $(0.203)$ & $(0.154)$ & $(0.086)$ & $(0.129)$ \\
F-stat. 1st stage & 20.69 & 30.53 & 35.41 & 34.79 \\
Sargan test (p-val) & 0.10 & 0.15 & 0.11 & 0.19 \\
$\mathrm{n}$ & 2759 & 2353 & 4185 & 4147 \\
& & & & \\
Obese 33 & -0.266 & -0.092 & 0.149 & 0.082 \\
& $(0.225)$ & $(0.194)$ & $(0.103)$ & $(0.176)$ \\
F-stat. 1st stage & 21.68 & 25.85 & 32.08 & 24.60 \\
Sargan test (p-val) & 0.03 & 0.05 & 0.77 & 0.13 \\
$\mathrm{n}$ & 2362 & 2132 & 3543 & 3694 \\
\hline
\end{tabular}

Basic controls, parental background, cognitive ability, and parental inputs ${ }^{* * *} \mathrm{p}<0.01,{ }^{* *} \mathrm{p}<0.05,{ }^{*} \mathrm{p}<0.1$ 
Table 6: Marginal effects and robust standard errors from first- difference employment regressions for males and females.

\begin{tabular}{lcccc}
\hline \hline & \multicolumn{2}{c}{ First-differences } & \multicolumn{2}{c}{ First-differences IV } \\
\hline & Males & Females & Males & Females \\
\hline$\Delta$ Obesity & $0.026^{*}$ & -0.033 & -0.268 & 0.455 \\
& $(0.015)$ & $(0.028)$ & $(0.368)$ & $(0.543)$ \\
1st stage F-stat. & & & 3.17 & 5.16 \\
Sargan test (p-val) & & & 0.27 & 0.57 \\
Observations & 3470 & 3578 & 3470 & 3578 \\
\hline
\end{tabular}

Controls for change in marital status and smoking status

Robust standard errors in parentheses

$$
\text { *** } \mathrm{p}<0.01,{ }^{* *} \mathrm{p}<0.05,{ }^{*} \mathrm{p}<0.1
$$

